\title{
A Comparative Analysis on the International Competitiveness of Sino-US Trade in Higher Education Service
}

\author{
SU Qiaoqin ${ }^{1, *}$, ZHOU Xiaofu² \\ ${ }^{1}$ Taizhou Institute of Science and Technology, Nanjing University of Science and Technology, China \\ ${ }^{2}$ CPC Party School of National Tax Institute, China \\ susiefanny@sina.com
}

\begin{abstract}
Under the background of economic globalization, the global trade of education service has seen a rapid development especially in some western developed countries which regard the education industry as an important service industry with great support and have gained substantial economic and social benefits. Since China's entry into the WTO, the trade volume of import and export has increased significantly between America and China, with one becoming a major trade partner of the other. In this thesis, a data analysis of the import and export volume in Sino-US higher education service trade has been made. And then by the use of the international competitiveness index, this thesis arrives at the conclusion that China, with its scale advantage, still has a weaker comprehensive competitiveness than America in the higher education service trade. In the end, the thesis puts forward strategies to improve China's international competitiveness in the development of higher education service trade .
\end{abstract}

Keywords: Sino-US, Higher Education, Trade in Higher Education Service, International Competitiveness, Education of Foreign Students

\section{Introduction}

Till the year 2015, China and the United States have enjoyed a diplomatic relationship for 36 years, during the time, the relationship has maintained a steady development, with extensive cooperation and exchanges in various fields such as economy and trade between China and the United States. Currently, these two countries both rank as one of the world's top economic entities. According to China's Customs, till November 2014, the Sino-US trade volume has exceeded \$502.5 billion, an increase of 204 times of $\$ 2.45$ billion in 1979. With the rapid development of Chinese economy, the economic and trade relations between the two countries continue to strengthen despite occasional contradictions and clashes. The two countries have become one another's second largest trade partners, and the relationship between the two countries has gradually grown into the world's most important bilateral relationship. Therefore, a study of the import and export volume, and an analysis of the development of Sino-American higher education service trade, can help further the service trade between China and the United States. On the other hand, the analysis of the international competitiveness of the higher education service trade of the U.S. and China can reveal the influential factors.

\section{Analysis of the current situation of the higher education service trade in the U.S. and China}

The following analysis of the development of higher education service trade of China and the United States is conducted from three aspects: the trade pattern, the development status quo, the trade development.

2.1 Analysis of the trade pattern of the higher education service trade in the U.S. and China According to the General Agreement on Trade in Service (GATS), except educational activities fully funded by the governments, commercial activities which demand tuition fall into the category of educational service trade, and all WTO members are entitled to the competition in the trade of education. With the development of economy and science and technology in the 21 st century, four trade patterns emerge in the international higher education service trade. 
Cross-border payments. Its main forms include remote education, electronic learning, and virtual university. Currently, for China and the U.S., it is still a relatively small market, but it has a great potential through the use of new information and communication technology, especially the Internet. Overseas consumption. Targeted at students who study abroad, it accounts for the largest market share in the global education service currently. Due to differences between Chinese and American economic development and consumption capacity, a huge gap exists between the export and import trade volume in China's higher education service, leading to a trade deficit in China while a trade surplus in the United States.

Commercial presence. It includes local branch institutions or satellite campuses, twinning partnership schools and teaching arranged by local franchises. Till September 2014, China has built 465 Confucius Institutes and 713 Confucius classes worldwide. Since the cooperation is mainly focused on the providing of language and cultural courses training services to overseas students.

Shift of natural persons. Usually this form involves professors, teachers, or researchers working abroad. Substantive operational demonstration on site calls for personal guidance of experts, so this form stands a good chance of becoming the main trade pattern in the higher education service trade between China and the United States in the future.

\subsection{Analysis of the development status quo of the higher education service trade in the U.S. and China}

In the development of education service trade of the two countries, China, an export power, occupies an important position in the input in the international education service trade market. The following is the analysis of the statistics of people who came to China and who went abroad for a higher education between 2004-2013, as is shown in Figure 1.

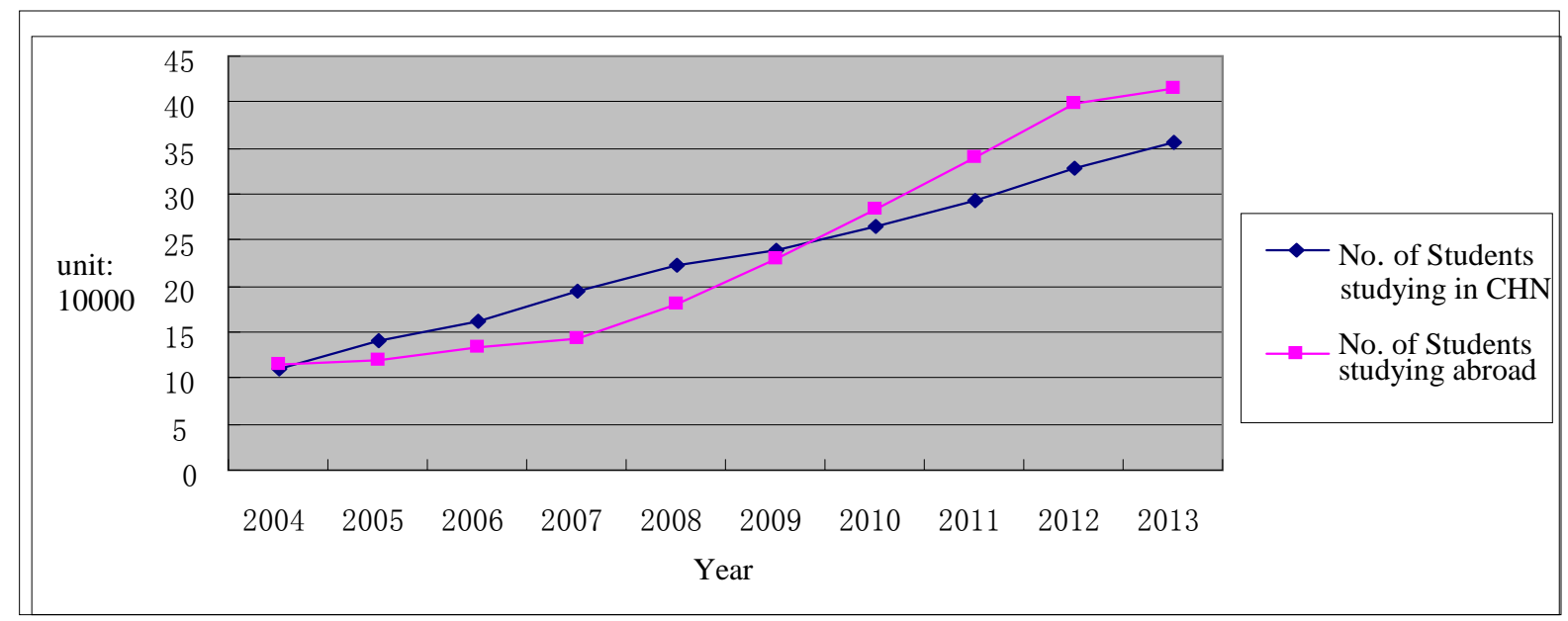

Figure 1. the statistics of people who came to China and who went abroad for a higher education between 2004-2013

Data source: China Education Yearbook by Chinese Ministry of Education

According to Fig.1, despite the number of people who came to China for education reached 356,500 in 2013, China was still an export country in the higher education service trade. Since 2004 there has been a rising trend for both people who came and went abroad for education. From 2005 to 2009, more people came to China to receive a higher education than those who went abroad. In 2009, parallel data appeared, which shows China's active development in international higher education trade and a relatively smooth trade status with other countries during this decade. Although in recent years, China's higher education has been in good condition, a problem remains for a long time, i.e. the uneven regional distribution of foreign students who came to China. It's clear that most Chinese international students came from developing countries such as Asia, and the proportion of foreign students from developed countries such as Europe and the United States was very small.

On the other hand, the United States has been ranking first in the import countries of the international higher education service trade. The following analysis is about America's ten major countries of destination and the number of students who went abroad to receive a higher education in 2012. Britain, 
Italy, Spain, France and China ranked as the top five countries of destination for American citizens to go abroad to receive a higher education in 2012, with China accounting for only $5.5 \%$ of the total number. This small amount of output shows China's lack of appeal to the American citizens.

According to the Open Doors Report on International Educational Exchange released by the Institute of International Education on 17th November 2014, from 2013 to 2014, there were about 886,000 international students studying at American colleges and universities, up 8\% year on year, reaching a record high. Among them, 274,000 Chinese students accounted for 31\%, a year-on-year growth of $17 \%$, followed by India and Korea, accounting for $12 \%$ and $8 \%$ respectively.

\subsection{Analysis of the trade development of the higher education service trade in the U.S. and \\ China}

According to the analysis of the Organization for Economic Cooperation and Development (OECD) in 2013, China has become one of the top ten global education service trade exporting countries. To sum up, China's service trade has been developing steadily.

The export volume of higher education service trade of China to America rose from 18 million in 2003 to 270 million in 2012, an increase of 15 times. And in contrast, a greater growth in import existed, from 1.253 billion in 2003 to 6.42 billion in 2012. The import volume rose straight upward, and the same trend appeared in the export volume, but with a smaller extent and a slower pace. Overall, China's import volume of higher education service trade was larger than its export volume to America, showing an increasing trade deficit, up to 6.15 billion in 2012 .

Based on the analysis above, a trade deficit exists in the service trade between China and the America, with the education service trade in a dominating position.

\section{Analysis of the international competitiveness of the higher education service trade in the U.S. and China}

Competitiveness of service trade can show the worldwide ranking of a certain industry of a certain country. In combination of the analysis above, this chapter calculates and analyzes the international competitiveness of higher education service trade of China and the U.S. by the use of service trade competitiveness index.

\subsection{Calculating results of international competitiveness of the higher education service trade in the U.S. and China}

The following are a couple of calculating methods of service trade competitiveness commonly used at present, i.e. CAI, RCA, and MSI.

3.1.1 Calculating results by CAI

CAI calculating results of the trade competitiveness of the higher education service trade in the U.S. and China between 2003 and 2012 are shown in Table 1.

Table 1. Change of CAI (2003-2012)

\begin{tabular}{lllllllllll}
\hline & $\mathbf{2 0 0 3}$ & $\mathbf{2 0 0 4}$ & $\mathbf{2 0 0 5}$ & $\mathbf{2 0 0 6}$ & $\mathbf{2 0 0 7}$ & $\mathbf{2 0 0 8}$ & $\mathbf{2 0 0 9}$ & $\mathbf{2 0 1 0}$ & $\mathbf{2 0 1 1}$ & $\mathbf{2 0 1 2}$ \\
\hline China & $\mathbf{- 0 . 4}$ & $\mathbf{- 0 . 6 5}$ & $\mathbf{- 0 . 6 5}$ & $\mathbf{- 0 . 5 4}$ & $\mathbf{- 0 . 4 3}$ & $\mathbf{- 0 . 3 7}$ & $\mathbf{- 0 . 3 4}$ & $\mathbf{- 0 . 2 9}$ & $\mathbf{- 0 . 3 1}$ & $\mathbf{- 0 . 3 4}$ \\
\hline US & $\mathbf{0 . 7 6}$ & $\mathbf{0 . 6 2}$ & $\mathbf{0 . 5 8}$ & $\mathbf{0 . 6 2}$ & $\mathbf{0 . 6 3}$ & $\mathbf{0 . 6 4}$ & $\mathbf{0 . 6 6}$ & $\mathbf{0 . 6 7}$ & $\mathbf{0 . 6 5}$ & $\mathbf{0 . 6 4}$ \\
\hline
\end{tabular}

Data source: Chinese Ministry of education and the American Statistical Yearbook 2012.

As is shown by Table 1, from the perspective of nationality, China has always been a net import country of higher education service trade, with a weak export competitiveness in service trade. In the long term, except for an obvious decline of CAI in 2003 and 2004, China showed a rapid change of competitiveness during the remaining years, with an average annual growth rate of 0.1 between 2005 and 2008, but a slow decline in 2010. On the contrary, the United States has been a net export country of higher education service trade, with a strong competitiveness. Especially after the drop of CAI from 2003 to 2005, the CAI has been fluctuating between 0.6 and 0.7 until 2012 .

Combined with the two data lines, the overall conclusion is that China has a low level of development in its higher education service trade, while the United States is far stronger and more competitive worldwide. 


\subsubsection{Calculating results by RCA}

To calculate RCA, statistics of the total exports of the world's higher education service and the world export volume from 2003 to 2012 are needed. The change of RCA of China's and American higher education service trade is shown in Table 2 as follows.

Table 2. Change of RCA (2003-2012)

\begin{tabular}{lllllllllll}
\hline & $\mathbf{2 0 0 3}$ & $\mathbf{2 0 0 4}$ & $\mathbf{2 0 0 5}$ & $\mathbf{2 0 0 6}$ & $\mathbf{2 0 0 7}$ & $\mathbf{2 0 0 8}$ & $\mathbf{2 0 0 9}$ & $\mathbf{2 0 1 0}$ & $\mathbf{2 0 1 1}$ & $\mathbf{2 0 1 2}$ \\
\hline China & 1.03 & $\mathbf{1 . 1 8}$ & $\mathbf{1 . 2 8}$ & $\mathbf{1 . 3 6}$ & $\mathbf{1 . 1 4}$ & $\mathbf{0 . 7 5}$ & $\mathbf{0 . 6 3}$ & $\mathbf{0 . 5 7}$ & $\mathbf{0 . 5}$ & $\mathbf{0 . 6 7}$ \\
\hline US & $\mathbf{2 . 0 3}$ & $\mathbf{3 . 2 1}$ & $\mathbf{3 . 2 7}$ & $\mathbf{3 . 4 2}$ & $\mathbf{2 . 3 1}$ & $\mathbf{1 . 7 2}$ & $\mathbf{1 . 8 6}$ & $\mathbf{2 . 0 2}$ & $\mathbf{2 . 3 4}$ & $\mathbf{3 . 0 8}$ \\
\hline
\end{tabular}

Data source: Chinese Ministry of education and the American Statistical Yearbook 2012.

As is shown in Table 2, the RCA of China between 2003 and 2007 was greater than 0.8, indicating moderate competitiveness in the higher education service trade, and during 2005 and 2006, RCA exceeded 1.25, the maximum data, showing a strong competitive power. However, it cannot be ignored that from 2008, RCA began a continuous decline, and the situation didn't improve until 2012. On the other hand, the index value of the United States fluctuated greatly, with the highest point of 3.42 in 2006 and the lowest point of 1.72 in 2008 . Even so, the RCA of its higher education service trade between 2004 to 2006 was more than 2.5, showing a strong competitiveness in the world, and remained so during the rest of years. The RCA shows, in 2012, of course, U.S. had obtained a very strong competitive power again, compared to the relative improvement of China's.

In brief, China has a moderate competitive power in its higher education service trade, still with room to improve, while the U.S. enjoys a strong competitiveness in its higher education service trade, not steadily but constantly. The stabilization of the index in the future will have a positive impact on the American higher education service trade development.

3.1.3 Calculating results by MSI

The calculating results are shown in Table 3.

Table 3. Change of MSI (2003-2012)

\begin{tabular}{lllllllllll}
\hline & $\mathbf{2 0 0 3}$ & $\mathbf{2 0 0 4}$ & $\mathbf{2 0 0 5}$ & $\mathbf{2 0 0 6}$ & $\mathbf{2 0 0 7}$ & $\mathbf{2 0 0 8}$ & $\mathbf{2 0 0 9}$ & $\mathbf{2 0 1 0}$ & $\mathbf{2 0 1 1}$ & $\mathbf{2 0 1 2}$ \\
\hline China & $\mathbf{0 . 0 3}$ & $\mathbf{0 . 0 3}$ & $\mathbf{0 . 0 4}$ & $\mathbf{0 . 0 5}$ & $\mathbf{0 . 0 6}$ & $\mathbf{0 . 0 5}$ & $\mathbf{0 . 0 4}$ & $\mathbf{0 . 0 5}$ & $\mathbf{0 . 0 5}$ & $\mathbf{0 . 0 5}$ \\
\hline US & $\mathbf{0 . 2 3}$ & $\mathbf{0 . 3 2}$ & $\mathbf{0 . 3 2}$ & $\mathbf{0 . 3 1}$ & $\mathbf{0 . 2 5}$ & $\mathbf{0 . 1 7}$ & $\mathbf{0 . 1 8}$ & $\mathbf{0 . 2 2}$ & $\mathbf{0 . 2 4}$ & $\mathbf{0 . 2 8}$ \\
\hline
\end{tabular}

Data source: Chinese Ministry of Education and the American Statistical Yearbook 2012.

The Table 3 above shows the average MSI of China during the ten years is only 0.045 , while that of the United States is 0.252 . The total weight of the world's higher education service trade in the international market was 0.31 , of which China accounted for less than $15 \%$, indicating a weak competitiveness. But American higher education service trade exhibited a prominent competitiveness.

As for the overall trend, the American MSI fluctuated greatly, while China's kept steady, but this index change trend does not represent China's great international competitiveness of higher education services trade.

\subsection{Analysis of the results of the international competitiveness of China's and American higher education service trade}

3.2.1 Influence of educational standards on the international competitiveness of higher education service trade

At present, China is in an urgent need of well-educated talents in the fields of science and technology, and management. It also needs to make effective use of quality international educational resources, and provides beneficial terms to attract superior talents, which in turn can promote China's internationalization of higher education and is one of the main reasons why countries around the world accelerate the development of higher education service trade nowadays. Yet, the highest level of a nation's academic civilization is embodied by the comprehensive strength of its institutions of higher learning in the educational standards. If China wants to enhance its core competitiveness in the process of globalization, its top priority is to speed up the academic civilization and improve the broad education of its institutions of higher learning. 
As a representative of western developed countries, the United States has been a net import country of higher education service trade, and attracts students from all over the world with its first-class academic research and teaching standards, and its unique academic culture. But quite a number of American universities still hope to enroll more international students to improve their international status.

3.2.2 Different ratios of higher education service trade in the service trade

It is well known that the service trade of developing countries falls behind that of developed countries a lot. As a developing country, China's service trade has a small share in the world's total and a low competitiveness in the modern service industry and service trade. In the previous section, we have calculated that China has a moderate competitiveness in the development of higher education service trade. The overall upgrading of its competitiveness is due to the large number of Chinese students who study abroad, but it does not mean China has advantages in the structure or index. It is still difficult for China to change the long-term monopoly of the United States and other western developed countries in the short run.

The United States international trade development had an early start, and is in a higher level than the world's average. Although with a lack of natural resources and labor, it still easily attracts labor input around the world, with its market environment and dominant position in world service trade. This also indirectly helps the assimilation of international student talents through the higher education service trade.

\section{Strategies to improve China's international competitiveness of higher education service trade}

As is shown above, China only enjoys a competitive edge in the scale of its education service trade, and the U.S. has a better development than China in its education service trade.

\subsection{Improvement of the education sectors by the Chinese government}

\subsubsection{Improvement of school qualities}

Various government departments should put into practice the scientific outlook on development, such as saving resources and protecting the environment, in all walks of life, gradually establish and perfect the credit mechanism, and effectively combine the higher education and the innovation of science and technology, as well as the production and employment. China also has to set up modern educational concept, further expand China's existing educational scale and improve the quality of its university, so as to attract more international students to China for a higher education, and further enhance the international competitiveness of China's higher education service trade.

4.1.2 Improvement of publicity of the market advantage of China's higher education

After entering the 21 st century, China has been actively strengthening the foreign propaganda of its study services, trying to provide enough information for foreign students with the intention of studying in China, through the international publicity agencies established by overseas embassies or Internet authentication. Taken from the experience of the United States, educational exhibition is one of the frequently used forms of publicity. Through the educational exhibition tour in the source country, characteristic running principles of schools are introduced, and range of potential candidates is expanded, thus attracting more students.

In addition, China also needs to make special improvement in the form of publicity, and exploit its comparative advantage to the fullest extent, by using all the means possible to provide information about its unique advantages in the education of Chinese language and culture, and China's traditional medical education.

\subsection{Positive support of educational reform from colleges and universities}

\subsubsection{Promotion of characteristic school-running policies}

The characters of the Chinese language and the language habits constitute a big barrier for foreign students. Consequently, Chinese colleges and universities should be realistic and arrange courses to improve foreign students' language proficiency, removing the language barrier and enhancing the international influence of Chinese language at the same time.Colleges and universities should lay 
special emphasis on the construction and reform of high-standard schools with international characteristics, using specialized courses with traditional Chinese characteristics as the breakthrough point and giving full play to the comparative advantages of disciplines in a leading position in the world, like Chinese language and culture, traditional Chinese medicine, genome research, and agricultural biotechnology. These disciplines have strong competitiveness in the international higher education service trade market, and thus can be exported firstly to other countries, in order to open a new door for the universities in aspects like quality higher education and international cooperation. 4.2.2 Establishment of educational brand of colleges and universities

With the continuous improvement of China's economic strength, and the constant enhancement of its impact on the international affairs, the international market of "studying in China" has also begun to heat up.With an increasingly fierce industry competition and an increasingly commodity-abundant market, public awareness of brands has exceeded the awareness of the product or service itself. Yuan Ziwen and Yuan Zihao, young writers of Peking University, are twin brothers, who were both admitted to one of China's leading universities with a common aspiration. The publication of their deeds in 1/2 of my world is always you, has become one of the new brands of Peking University. So today in the globalization of education, the educational institutions should strengthen the construction and management of their brands so as to cultivate the advantage of higher education.

4.2.3 Improvement of Teaching ecological environment

Compared with China, economically and educationally advanced foreign countries have a relatively good natural environment, and a better campus environment, teaching environment and educational environment between the teachers and the students.Quality colleges and universities in China should be encouraged to open cooperative branch campuses abroad to expand its scope of radiation and increase popularity. Outstanding college management teams from home and abroad should also be introduced to recruit backbone teachers and conduct effective research on teaching projects.

\section{References}

[1] Xubin, Lixin. A Quantitative Comparison of the International Competitiveness of Chinese and American Overseas Education Service Trade [J]. Management and Administration, 11(2013),p106 108.

[2] Hanqi, Wang Jiankun. A Study on the Trade Deficit of China's Higher Education Services [J]. Intertrade, 4(2012), p62 66.

[3] Lu Yonghong. Analysis of the Competitiveness of China's Education Service Trade and the Countermeasures [J]. International Trade, 18(2011),p50 51.

[4] U.S. Department of State. Fact Sheet on the International Educational Exchange Program,1946-1966[EB/OL].[2013-06-12].http://files.eric.ed.gov/fuIltext/ED019027.pdf.

[5] UNESCO. Mid-Term Strategy (2002^2007)[EB/OL].[2013-05-28].

http://unesdoc.unesco.org/images/0012/001254/125434e.pdf

[6] OECD (2012), Education at a Glance 2012: OECD Indicators.

[7] OECD (2013), Education at a Glance 2013: OECD Indicators.

[8] OECD (2014), Education at a Glance 2014: OECD Indicators.

[9] OECD Statistics on International Trade in Services, volume 2013/1

[10] http://dx.doi.org/10.1787/eag-2013-en 